the intestine by bile and digestive juices is in progress were stressed, and further parallels drawn between relatively abundant elements such as calcium and magnesium and trace elements such as strontium, tin, cobalt and nickel.

In his final summary of the day's discussion, Prof. C. Harington reviewed a number of the salient features in the light of his own experience of the history of development of the physiology of iodine, stressing the point that although much information on the importance of various trace elements may accumulate, final conviction concerning the significance of any particular one does not really penetrate the scientific consciousness of the community until precise physiological function becomes clear and the actual operative mechanism is biochemically demonstrated.

T. DALLING.

H. H. Green.

\section{STAR MAGNITUDES AND IMAGE DIAMETERS IN PHOTOGRAPHIC PHOTOMETRY}

$\mathrm{F}_{\mathrm{s}}$ ORMULA hitherto employed to determine the relationship between star magnitudes and image diameters on photographic plates have been empirical, and fail in certain circumstances. It is impossible to apply them in the case of bright stars which give diameters larger than a certain limiting value (and this value varies with different formulæ) and, in addition, the formulæ take no account of the effect of star colours. D. L. Edwards has described a new method of investigation which gives very satisfactory results (Mon. Not. Roy. Astro. Soc., 102, 5). The work was carried out at the Norman Lockyer Observatory, Sidmouth. Three different Zeiss triplet lenses were used : (a) apertyre $14 \mathrm{~cm}$., foeal-length $70 \mathrm{~cm}$., (b) aperture $10.4 \mathrm{~cm}$., focal-length $50 \mathrm{~cm} .,(c)$ similar to (b) but stopped down to $2 \mathrm{~cm}$. aperture. The plates used were the Barnet Super Press (blue sensitive emulsion), and Ilford Hypersensitive Panchromatic, which gives a good scale of photovisual magnitudes without a filter. When the panchromatic plates were considered and measured diameters were plotted against H.D. visual magnitudes (only stars of type $A 0$ being used to determine the form of the relation for one colour only) the empirical formula $m=a-b\left(D-k D^{2}\right)$ gave the best fit. In this formula $m$.is the magnitude, $D$ the diameter, and $a, b, k$ are constants.

Measures made on Barnet Super Press plates were treated in the same way, except that photographic instead of photovisual magnitudes were used, and it was found that the above relation held as for the photovisual plates. In addition, the same values of $k$ were also applicable, in spite of the different magnitude scales and of the different types of emulsion used. Good values of $k$ were given by $k=10^{-5}(140-13 C)$, where $C$ is the colour index.

The advantage of the first formula given above is that it has a greater range of application to bright stars than earlier formulæ, and it also allows for colour effect.

Edwards has applied this formula to $\gamma$ Cassiopeiæ. The series of photographs extended over the period June 1, 1940, until March 24, 1942. During 1940 the magnitude variations were more pronounced, but by the end of the year and also throughout 1941 they tended to become steadier. Considerable changes in the spectrum accompanied the more pronounced fluctuations. At, and just preceding, the minima of June 29, 1940, photovisual magnitude $2 \cdot 76$ and photographic magnitude $2 \cdot 64$, and also of September 21, photovisual and photographic magnitude each $2 \cdot 53$, the $H$ lines showed well-separated double emission components with strong central absorption and rather faint 'dish-shaped' absorption fringes. The $\mathrm{He} I$ absorption lines at $4471,4026,3964$ were strong and sharp, and O II absorption rather faint. During the rise to maxima at August 24 and October 7, the magnitudes on these dates being $m_{p v}=2 \cdot 20$, $m_{p}=2 \cdot 06, m_{p v}=2 \cdot 05, m_{p}=2 \cdot 06$ respectively, the $H$ central absorption became fainter and the "dishshaped' absorption stronger. The He I lines became fainter and more diffuse, OII became a little stronger, and $\lambda 3888(\mathrm{He} \mathrm{I})$ very strong.

It was found that the colour index changes were subject to considerable uncertainty and did not show such pronounced correlation with spectrum changes as the magnitude variations. The mean colour index over the whole period was -0.12 , and corresponds to the average colour index of $B 6$ stars. As $\gamma$ Cassio. peiæ is a $B 2$ star, the average colour index of which is $-0 \cdot 30$, its average colour index suggests considerable reddening.

\section{ULTRA-SHORT RADIO WAVE PROPAGATION}

A $T$ a meeting of the Wireless Section of the A Institution of Electrical Engineers on November 4, Dr. R. L. Smith-Rose and Miss A. C. Stickland read a paper describing the results of an analysis of field intensity measurements obtained during the years 1937-39, over the Post Office radio-telephone link between Guernsey and Chaldon, England, on wave-lengths of 5 and $8 \mathrm{~m}$. (frequencies 60 and 37.5 mc. $/ \mathrm{s}$.). The path between the radio stations was almost entirely over sea and about 85 miles in length, of which some 36 miles were outside the optical range. The material analysed was in the form of continuous, twenty-four hours a day, records of the field intensity received at Chaldon from the transmitters at Guernsey.

A quantitative study of the records confirmed the similarity of the type of signal fading on the two wave-lengths, and the lack of both diurnal and true annual variation; on the other hand, the results suggested a long-term secular variation in which the amount of fading on $5 \mathrm{~m}$. tended to increase to a maximum over the period of observations while that on $8 \mathrm{~m}$. decreased. The period of two years over which the observations were taken was not suificient, however, to allow of any conclusions being formed as to an explanation of this trend.

Comparison with meteorological data showed a marked correlation between periods of very little fading and the presence of low-pressure systems, while periods of slow fading recurred at times of anticyclonic conditions. This, together with the fact that fading, while always less in winter than in summer, showed no regular seasonal variation, led to the conclusion that the winter decrease was due to the greater prevalence of low-pressure systems during this season. 
A simple theoretical treatment of the propagation of waves through the lower atmosphere shows that account must be taken of the various paths by which rays can pass from transmitter to receiver, these rays being subject to diffraction, refraction or reflection on the way. The received signal is the resultant of the various rays received, and it is clear that interference effects may result from the arrival of two rays simultaneously by different paths. Sudden changes in the temperature and water vapour content in the atmosphere produce corresponding changes in refractive index and so cause marked bending of the rays transmitted. In regions of temperature inversion these conditions may be specially marked, resulting in the ray being completely bent over and returned to earth in a manner analogous to reflexion from a discontinuity.

An explanation of the lack of fading in bad weather and of the pronounced fading in good weather is sought in the fact that, in anticyclonic conditions, temperature inversions and associated sudden changes in relative humidity are usually present at heights of 1-2 miles, whereas in cyclonic or depression conditions these are absent. While the existence and diurnal variations of temperature inversions may be different over land and over sea, the general structure of the atmosphere in an anticyclone is probably the same in the two cases; in particular, changes in water vapour content may obtain over sea, which give rise to refraction in the lowest layers, and thus cause sufficient bending of the direct rays to account for the received signal and its variations. As mentioned above, rapid fading occurred mainly on the wave-length of $5 \mathrm{~m}$. and was usually superposed on flat or steady records and was present only in winter. It is thought that this is probably a shimmering effect due to turbulence in the atmosphere during bad weather. A similar effect had previously been noted by Ross Hull in the United States and was attributed to the same cause.

A more detailed study of the radio phenomena on the above lines has not been possible on account of the limitations imposed by the nature of the meteorological information available at the place and for the period of the wireless observations. In future investigations, this limitation may be at least partly removed, by improved meteorological technique for studying conditions in the lower atmosphere, and by making arrangements for special and close co-operation between those responsible for the wireless and meteorological observations.

\section{FORTHCOMING EVENTS}

Monday, January 4-Wednesday, January 6 agriodutural Ed GCation Association (at the Midland Agricultural College, Sutton Bonington, Loughborough). Conference.

\section{Monday, January 4}

SOCIETY OF CHEMICAL INDUSTRY (FOOD GROUP, PLASTICS GROUP

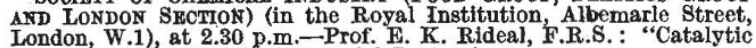
London, W.1), at 2.30 p.m.- Prof. K. K. Ride

\section{Friday, January 8}

INBTTPUTION OF MRChANIOAL ENGINBRRS (at Storey's Gate, st. James's Park, London, S.W.1), at 5.30 p.m.-Mr. C. C. Pounder; "Some Types of Propelling

(Thomas Lowe Gray Lecture). (at the Mining Institute, Newcastle-upon-Tyne), at 6 p.m.-Mr. C. Le Maistre: "War-Time Standardization".

\section{Saturday, January 9}

AsSOCIATION OF SCIBNTIFIO WORKRRS (in the Lecture Theatre of the London School of Hygiene, Keppel Street, London, W.C.1), at 2.15 p.m.-Conference on Problems connected with the Organisation, Application and Personnel of the Medical Sciences. (Chairman: Dr. D. McClean.)

\section{APPOINTMENTS VACANT}

APPLICATIONS are invited for the following appointments on or be. fore the dates mentioned:

LeOTURER in Mhchanical ENGinkering-The Principal, Heriot. Watt College, Edinburgh (January 7).

Assistant to THE ADVISORX OFTIORR IN ANIMAL HUSBANDRYThe Secretary, West of Scotland Agricultural College, 6 Blythswood Square, Glasgow (January 8).

Woman PSYchologist for service at the Child Guidance ClinicThe Chief Education Officer, Education Office, Council House, Margaret Street, Birmingham 3 (January 9).

REGIUS PROFrsSOR OF GEOLOGY at Edinburgh University-The Private Secretary, Scottish Office, Fielden House, 10 Great College Street, London, S.W.1 (January 11).

SCIENCE GRADUATE (BOTANY), with experience in abstracting and knowledge of languages desirable- The Deputy Director, Imperi

RUSSIAN TRANSLATOR to work on literature in Agricultural Botany

RUSSIAN TRANSLATOR to work on literature in Agricultural Botany Genetics, Cambridge (January 16).

HoNOURS GRADUATE TO TEACH BIology in the Bede Collegiate Girls' School-The Director of Education, 15 John Street, Sunderland (January 18).

LABORATORY STEWARD for the Veterinary Laboratory-The Veterinary Investigation Offcer, University College of North Wales, Bangor (January 18).

THRER JUNIOR ELECTRICAL INSPECTORS OF MINES-The Ministry of Labour and National Service, Central (Technicsl and Scientiffc Register (Section D.521), Sardinia Street, Kingsway, London, W.C.2.

\section{REPORTS and other PUBLICATIONS (not included in the monthly Books Supplement)}

\section{Great Britain and Ireland}

Why India? By Reginald Reynolds. Pp. 28. (London: Was Resisters' International.) $6 d . \quad$ [2112 Gas Research Board. Communication GRB7a: 33rd Report of the Refractory Materials Joint Committee. Abridged edition. Pp. 8 . Institution of Gas Engineers. Communication No. 249: Report of the committee of Enquiry on Gas Quality. Pp. 10. Communication No. 250: Report of the Committee of Enquiry on Sulphur Removal. Pp. 10. Communication No. 251: Report of the Committee of Enquiry on Standardization of Appliances, Part 1: Domestic Gas Cookers. Pp. 16. Communication No 252: Report of the Committee of Enquiry on Coke Quality, Part 1: Sizing of Coke. Pp. 8. Communication No. 253: 3rd Report of the Chairmen's Technical Committee, 1941-42, Pp. 18. Communication No. 254: 19th Report of the Gas Education Committee, 1941-42. Pp. 24. (London: Institution of Gas
Engineers.)

\section{Other Countries}

U.S. Department of Agriculture. Technical Bulletin No. 828: Further Studies on the Removal of Spray Residues from Eastern. Grown Apples. By M. H. Haller, C. C. Cassil, Edwin Gould and A. L. Schraeder. Pp. 32 . (Washington, D.C.: Government Printing
O2112

British Honduras. Abridged Report of the Forest Department for the Year ended 31st December 1941. Pp. 4. (Belize: Forest De. partment.)

Forest Research Institute, Dehra Dun. Indian Forest Leaflet No. $22:$ Possible War-Time Sourees of Vegetable Rubber in India. By T. V. Dent. Pp. iv +16. 4 annas; 6d. Indian Forest Leaflet No. 26: Rectangular Plywood Containers. Pp. ii $+2+1$ plate. 4 annas; $6 d$. Indian Forest Leaflet No. 27: Notes on some Aspects of Erosion Control. By Jagdamba Prasad. Pp. v+18. 4 annas ; 6d. (Dehra
Dun: Forest Research Institute.) University of Bombay: Department of Chemical Technology. Annual Report, 1941-42. Pp. iv +28. (Bombay: The Univer. sity.)

Smithsonian Miscellaneous Collections. Vol. 103, No. 5: New Upper Cambrian Trilobites. By Charles E. Resser. (Publication 3693 . Pp. iii + 136. (Washington, D.C.: Smithsonian Institution.) [2412 Annual Report of the Agricultural Department, Dominica, 1841 Pp. 4. (Roseau : Agricultural Department.)

\section{Catalogues}

A Catalogue of Books and Periodicals on Entomology, together with a Selection of Recently Acquired Books on General Natural History. (No. 606.) Pp. 24. (London: Bernard Quaritch, Ltd.) 